
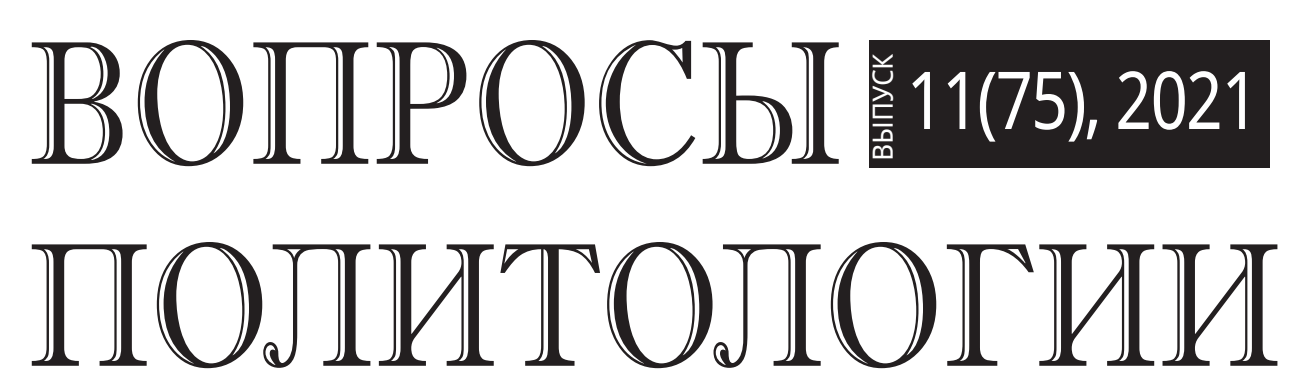

Научный журнал

Журнал «Вопросы политологии» включен

в Перечень рецензируемых научных изданий

ВАК при Министерстве науки и высшего образования РФ

по политическим наукам, в которых должны быть опубликованы основные научные результаты на соискание ученой степени кандидата наук, на соискание ученой степени доктора наук

Журнал включен в Перечень научных изданий рекомендованных ВАК Республики Узбекистан для публикации основных научных результатов диссертаций по политическим и философским наукам 
Председатель Редакционного Совета - ПЛАТОНОВ В.М.,

к.ю.н., заведующий кафедрой политического анализа и управления РУДН,

Председатель Московской городской Думы (1994-2014 гг.)

\section{Редакционный Совет}

АВАЗОВ

Камиль Халлиевич

\section{АСТВАЦАТУРОВА}

Майя Арташесовна

БЛОХИН

Владимир Владимирович

БОЖАНОВ

ВАНКОВСКА

Биляна

\section{ВЕДРИН}

Оливье

Наталия Михайловна

ГОНЧАРОВ

Пётр Константинович

ГРАЧЁВ

Михаил Николаевич

ДЭМБЭРЭЛ К.

ДОНАЙ

Лукаш

ЖИЛЬЦОВ

Сергей Сергеевич

КАРАДЖЕ

Татьяна Васильевна

КАССАЕ НЫГУСИЕ

В. МИКАЭЛЬ

КОВАЛЕНКО

Валерий Иванович

КОМЛЕВА

Валентина Вячеславовна

КРИВОКАПИЧ

Борис

МЕДВЕДЕВ

Николай Павлович

МИХАЙЛОВ

Вячеслав Александрович

НАЗАРОВА

Елена Александровна

НАЗАРОВ

Александр Данилович

НАСИМОВА

Гульнара Орленбаевна

НИСНЕВИЧ

Юлий Анатольевич

ОРЛОВ

Игорь Борисович

ПАХРУТДИНОВ

Шукритдин Ильясович

ПЛЯЙС

Яков Андреевич

ПРЯХИН

Владимир Федорович

ПУСЬКО

Виталий Станиславович

СЛИЗОВСКИЙ

Дмитрий Егорович

СЫЗДЫКОВА

Жибек Сапарбековна

ХОПЁРСКАЯ

Лариса Львовна

ШАРКОВ

Феликс Изосимович

ЯН ФУЛИНЬ
Владимир Александрович

ВЕЛИКАЯ

д.ф. (PhD) по полит. наукам, Региональный центр переподготовки и повышения квалификации работников народного образования Сурхандарьинской области (Узбекистан, г. Ташкент) д.П.н., профессор, Пятигорский государственный университет (Россия, г. Пятигорск) д.и.н., профессор, РУДН (Россия, г. Москва)

д.и.н., профессор, Белорусский Национальный технический университет (Белоруссия, г. Минск)

профессор политологии и международных отношений

факультета философии Университета Святых Кирилла и Мефодия

(Македония, г. Скопье)

профессор, ректор «Континентального университета в Киеве»

(Франция, г. Париж)

д.п.н., профессор, ИСПИ ФНИСЦ РАН, РГГУ (Россия, г. Москва)

д.с.н., профессор, Российский университет транспорта (МИИТ)

(Россия, г. Москва)

д.П.н., профессор, РГГУ (Россия, г. Москва)

доктор (PhD), Институт международных отношений АН Монголии (Монголия, г. Улан-Батор)

д.п.н., профессор, Университет им. Адама Мицкевича в Познани (Польша, г. Познань)

д.П.н., профессор, Дипломатическая академия МИД РФ

(Россия, г. Москва)

д.ф.н., профессор, МПГУ (Россия, г. Москва)

д.и.н., профессор, РУДН (Россия, г. Москва)

д.ф.н., профессор, МГУ им. М.В. Ломоносова (Россия, г. Москва)

д.с.н., профессор, РАНХиГС при Президенте РФ (Россия, г. Москва)

д.ю.н., Унион-Никола Тесла университет (Сербия, г. Белград)

д.п.н., профессор, главный редактор журнала (Россия, г. Москва)

д.и.н., профессор, РАНХиГС при Президенте РФ (Россия, г. Москва)

д.с.н., профессор, МГИМО МИД России (Россия, г. Москва)

д.и.н., профессор, МАИ (Россия, г. Москва)

д.п.н., профессор, Казахский Национальный университет

им. Аль-Фараби (Казахстан, г. Алматы)

д.п.н., профессор, НИУ «Высшая школа экономики»

(Россия, г. Москва)

д.и.н., профессор, НИУ «Высшая школа экономики»

(Россия, г. Москва)

д.п.н., профессор, Институт переподготовки и повышения

квалификации руководителей и специалистов системы народного

образования имени А. Авлони (Узбекистан, г. Ташкент)

д.и.н., Д.П.н., профессор, Финансовый университет при Правительстве РФ (Россия, г. Москва)

д.п.н., профессор, РГГУ (Россия, г. Москва)

д.ф.н., профессор, ВА РВСН им. Петра Великого (Россия, г. Москва)

д.и.н., профессор, РУДН (Россия, г. Москва)

д.и.н., профессор, ИСАА МГУ им. М.В. Ломоносова

(Россия, г. Москва)

д.П.н., профессор, Киргизско-Российский славянский университет

(Киргизия, г. Бишкек)

д.с.Н., профессор, РАНХиГС при Президенте РФ (Россия, г. Москва)

проректор Хэйлунцзянского института иностранных языков (КНР, г. Харбин)

\section{Редакционная коллегия}

Главный редактор - МЕДВЕДЕВ Н.П., д.П.Н., профессор

Абрамова О.Д. (д.П.н.)

Насимова Г.О. (д.п.н.)

Кетцян Г.В. (к.П.н. - зам. гл. редактора)
Шкурина С.С. (к.П.н. - ответ. редактор)

\section{ЖУРНАЛ ВКЛЮЧЕН В ПЕРЕЧЕНЬ ВАК РФ}

\author{
УЧРЕЖДЕН \\ ООО «Издательство \\ «Наука сегодня»
}

Журнал зарегистрирован

Федеральной службой

по надзору в сфере массовых коммуникаций, связи и охраны культурного наследия

Рег. № ПИ № ФС77-46176 от 12 августа 2011 г.

Журнал издается ежемесячно

Журнал включен в базу РИНЦ

(Российский индекс

научного цитирования)

Включен в каталог

Ulrich's Periodicals Directory

Пятилетний импакт-фактор: 1,489.

Адрес редакции:

115598 , г. Москва, ул. Загорьевская, д. 10, корп. 4, цокольный этаж, помещение I, комната 7-1, офис 4

Тел.: (910) 463-53-42

Интернет-ресурс:

www.voprospolitolog.ru

E-mail: voprospolitolog@yandex.ru

Мнение авторов может не совпадать с мнением редакции.

При перепечатке ссылка

на журнал обязательна.

Научные статьи, публикуемые в журнале подлежат обязательному рецензированию.

Ответственный редактор Шкурина С.C.

Перевод

Чернышова Е.B.

Компьютерная верстка Анциферова А.С.

Подписано в печать 25.11.2021

Формат 60×84/8. Объем 24,3 Печать офсетная Тираж - 1000 эКз.

(1-й завод - 500 экз.) Заказ № 000.

Отпечатано в типографии OOO «Белый ветер»

115054, г. Москва, ул. Щипок, 28 Тел.: (495) 651-84-56 
ISSN 2225-8922 (print)

12 выпусков в год и

4 выпуска в год переводной (англ.) версии

Языки: русский, английский

http://voprospolitolog

Входит в перечень рецензируемых научных изданий ВАК РФ Включен в каталог периодических изданий Ульрих

(Ulrich's Periodicals Directory: http://www.ulrichsweb.com)

Материалы журнала размещаются на платформе РИНЦ

Российской научной электронной библиотеки, Electronic Journals Library Cyberleninka

Подписной индекс издания в каталоге агентства Роспечать 70035

\section{Цели и тематика}

Журнал ВОПРОСЫ ПОЛИТОЛОГИИ - периодическое международное рецензируемое научное издание в области политических исследований. Журнал является международным как по составу редакционного совета и редколлегии, так и по авторам и тематике публикаций.

Научный журнал издается с 2011 года в издательстве «Наука сегодня». С 2016 года издается переводная (англ.) версия журнала. С момента своего создания, журнал ориентировался на высокие научные и этические стандарта и сегодня является одним из ведущих политологических журналов России.

Цель журнала - способствовать научному обмену и сотрудничеству между российскими и зарубежными политологами.

Журнал предназначен для публикации результатов фундаментальных и прикладных научных исследований. Тематическая направленность журнала отражается в следующих постоянных рубриках: «История и философия политики», «Политические институты, процессы и технологии», «Политическая регионалистика и этнополитика», «Политическая культура и идеологии», «Политические проблемы международных отношений и глобализации».

Формат публикаций: научные статьи, обзорные научные материалы, материалы круглых столов, научные рецензии, научные сообщения, посвященные исследовательским проблемам в сфере политики и политологии.

В своей деятельности редакционный совет и редколлегия журнала руководствуется принципами, определяемыми ВАК России для научных журналов, в том числе: наличие института рецензирования для экспертной оценки качества научных статей; информационная открытость издания; наличие и соблюдение правил и этических стандартов представления рукописей авторами.

Целевой аудиторией журнала являются российские и зарубежные специалисты-политологи, а также аспиранты и магистры, обучающиеся по направлениям политология, государственное и муниципальное управление и международные отношения.

Журнал строго придерживается международных стандартов публикационной этики, обозначенных в документе СОРЕ (Committee on Publication Ethics) http://publicationethics.org

Полные сведения о журнале и его редакционной политике, требования о подготовке и публикации статей, архив (выпуски c 2011 года) и дополнительная информация размещена на сайте: http://voprospolitolog.ru

Электронный адрес: voprospolitolog@yandex.ru

ISSN 2225-8922 (print)

12 issues a year plus 4 issues a year of the translated (eng.) version Languages: Russian and English http://voprospolitolog

Included in the list of peer-reviewed scientific publications of the Higher Attestation Commission of the Russian Federation Included in the Ulrich's Periodicals Directory Materials of the journal are placed on the RSCI platform of the Russian scientific electronic library - Electronic Journals Library Cyberleninka Subscription index of the journal in the Rospechat Agency catalogue is: 70035

\section{Objectives and themes}

Academic journal "Political Science Issues" is an international peer-reviewed scientific periodical in the field of political studies. The journal has an international character because of the composition of its Editorial Board, its editors, its contributing authors and topics of its publications.

The scientific journal is published since 2011 at the "Publishing House "Science Today". Translated (eng.) version of the journal is published since 2016. Since its inception, the journal was guided by high scientific and ethical standards and today it is one of the leading political science journals in Russia.

The purpose of the journal is to promote scientific exchange and cooperation between Russian and foreign political scientists.

The journal is intended for the publication of the results of fundamental and applied scientific research. Thematic focus of the journal is reflected in the following permanent headings: "History and philosophy of politics," "Political institutions, processes and technologies," "Political regionalism and ethno-politics," "Political culture and ideologies," "Political problems of international relations and globalization."

Format of publications: scientific articles, reviews, scientific materials, materials of round tables, scientific reviews, scientific reports devoted to research problems in the field of politics and political science.

The Editorial Board and the editors of the journal in their activities are guided by the principles defined by VAK of Russia for scientific journals, including: presence of the institute of peer review for the expert quality assessment of scientific articles; information openness of the publications; availability and compliance with the rules and ethical standards for the submission of manuscripts by the authors.

The target audience of the journal is Russian and foreign specialists-political scientists, as well as graduate students and masters in the fields of political science, state and municipal management and international relations.

The journal strictly adheres to the international publishing standards and publication ethics identified in the COPE (Committee on Publication Ethics) document. http://publicationethics.org.

Full details of the journal and its editorial policy, requirements to the preparation and publication of articles, archive (issues since 2011) and additional information are available on the website: http://voprospolitolog.ru

E-mail address: voprospolitolog@yandex.ru 


\section{ИСТОРИЯ И ТЕОРИЯ ПОЛИТИКИ}

Гончаров П.К. Современная политическая культура:

к определению понятия 3008

Солодова Г.С. Поиск универсальных закономерностей критический взгляд Р. Будона на теории социальных изменений. 3014

Берёзкина E. Ю. Вариации интерпретации популизма

в современной политологии..... 3020

\section{ПОЛИТИЧЕСКАЯ ИСТОРИЯ РОССИИ}

Гаджиев М.M. Драматическая эволюция государственно-конфессиональных отношений в Республике Дагестан в постсоветский период: от религиозно-политической конфронтации до региональной стабилизации 3028

Наледин И.И. Политические партии

Крымского полуострова и их влияние на избирательную систему Крыма в постсоветский период

\section{ПОЛИТИЧЕСКАЯ СОЦИОЛОГИЯ}

Абрамова М.А. Применение социокультурного

и интеракционисткого подходов в изучении трансформаций социокультурного пространства

Макаренко К.М., Панкратов С.А., Панкратова Л.С.

Трансформация гражданского протеста в современной России:

выбор форм онлайн и офлайн активности.

Цуприк М.И. К вопросу об исследовании

инструментария изучения политической идентичности.

\section{ПОЛИТИЧЕСКИЕ ИНСТИТУТЫ, ПРОЦЕССЫ И ТЕХНОЛОГИИ}

Володина Н.А., Ретинская В.Н. Особенности реализации российской государственной антикоррупционной политики в условиях информационного общества и электронного государства.

Андреева Ю.В., Липатова A.B. Факторы влияния политических традиций на технологии конструирования медиаобраза регионального лидера.

Калиев И.А., Алтыбасарова М.А. Информационные технологии в политическом процессе: политологический анализ ....

Прончев Г.Б., Михайлов А.П. Виртуальные социальные среды интернета как инструмент политической борьбы

Алексеев Р.А., Еж⿻в Д.А., Шакурова Н.Е. Практика организации электронных референдумов в России: особенности апробации .

Добрынина М.В., Огородов Д.А. Формирование советской политики в области физкультуры, спорта и спортивного образования: идеологические основания 
Мадюкова $\boldsymbol{C}$. . Н. Национальная политика

в социокультурном пространстве региона

(на примере Республики Алтай).

Николенко $\boldsymbol{A}$. $A$. Легитимация властных структур и ее особенности

в рамках концепции «русской локальной цивилизации»

Ocunoв A.B. Социально-политический мониторинг

и социально-медийная предиктивная аналитика как инструменты

и технологии консолидации политической власти

Сабирова H.C. Влияние средств массовой информации

на политическую культуру современной России

Лапшина Д.М., Попов С.И. Кадровая политика государственной

гражданской службы России на современном этапе

и пути ее совершенствования

Калиниченко A.O. Российский федерализм

в развилке конституционной реформы

Файзиев 3. Влияние религиозной толерантности

на межнациональные отношения

Лебедева $\boldsymbol{E}$. $\boldsymbol{A}$. Снижение проходного барьера

и наличие графы «против всех» как показатели

демократичности выборов в современной России

Малахов А.А. Концепция всеобщего благосостояния

и ее реализация в целях и функциях государства

Романова Ю.А. Развитие научно-технической

инновационной инфраструктуры субъектов Российской Федерации,

входящих в состав ЦФО

Салимов Д.М. Политическая цензура

и сетевые СМИ в современном Таджикистане

\section{ГОСУДАРСТВЕННОЕ УПРАВЛЕНИЕ И ОТРАСЛЕВЫЕ ПОЛИТИКИ}

Жолманов А.С., Афонин М.В., Кривова А.Л. Коррупционные риски

как категория антикоррупционной политики.

ТЕОРИЯ И ИСТОРИЯ МЕЖДУНАРОДНЫХ ОТНОШЕНИЙ И ВНЕШНЕЙ ПОЛИТИКИ

Абрамов В.Л., Прокофьев В.А. Устойчивые конкурентные

преимущества стран в контексте эволюции теоретических подходов

по развитию мировой торговли

Юрасов И.А., Володина Н.А. Историческая память

российской молодежи как основа формирования

государственно-ориентированной личности

Тушков А.А., Животова Д.А. Вестернизация Японии

как импрувер культурного кроссинговера 
Чемшит А.А., Ковалевский А.А. Глобальные

и европейские противоречия в современном

геополитическом дискурсе в Болгарии (Часть II)

Воронина H.A. Механизмы транснациональной коммуникации

в сфере миграции в современную эпоху.....

Агоннуде Бидолей Вианней Фредди. Приоритеты ЮАР в G20 .

Хабаров И.А. Маршруты символического

конструирования пространства:

от составления карты к штурму горизонтов

Чучин М.И., Адутов Р.P. Система поддержки принятия

решений в деятельности различных организаций

Иванченко М.A. Развитие политической системы

Аргентины в 30-40 годы ХХ века

Баракат Kaйс A.M. Внешняя политика США по отношению

к арабо-израильскому конфликту на современном этапе.

Казарян С.A., Бозоян T.P. Корпоративная социальная деятельность

транснациональных корпораций Соединенных Штатов Америки

в странах Юго-Восточной Азии

Власов A.B. Современные технологии публичной дипломатии

$\boldsymbol{E} \boldsymbol{\varepsilon}$

для контроля за деятельностью мировых ТНК

Золотарев H.A. Зарубежный опыт интеграции мигрантов:

практика современной Германии.

Клюкин Н.Д. Цифровая дипломатия в эпоху больших данных

Лебедева Е.И., Присекин А.А. Современное политическое

лидерство в Европе в контексте религиозного ренессанса

Петросян Ф.A. Политическая активность в шведском Риксдаге

сторонников и противников присоединения к НАТО

Симонова А.И. Анализ государственной политики Китая в области молодежных браков

Фаздалова Р. Политическая значимость Казани

в развитии китайско-российских отношений

Дуань Жань. Взаимодействие КНР со странами Центральной Азии

в области безопасности в рамках ШОС

Нина Рамос Росио Леонор. Внешнеполитический

вектор Бразилии в условиях становления нового мирового порядка

Добромыслов А.С. Политические аспекты глобального старения

\section{СТУДЕНЧЕСКАЯ НАУКА}

Лю Лу. США и Россия на пороге новой холодной войны. 
кандидат политических наук,

судья Ленинского районного суда г. Ростова-на-Дону, Россия, г. Ростов-на-Дону

\section{СОЦИАЛЬНО-ПОЛИТИЧЕСКИЙ МОНИТОРИНГ И СОЦИАЛЬНО-МЕДИЙНАЯ ПРЕДИКТИВНАЯ АНАЛИТИКА КАК ИНСТРУМЕНТЫ И ТЕХНОЛОГИИ КОНСОЛИДАЦИИ ПОЛИТИЧЕСКОЙ ВЛАСТИ}

Оиенивая данные, полученные центрами опроса общественного мнения и СМПА в 2020-2021 г2., автор обосновывает вывод, что социальнополитический мониторинг и социиально-медийная предиктивная аналитика (СМПА) являются эффективными востребованными инструментами u технологиями консолидации политической власти, способными предоставить необходимую для обеспечения государственной консолидационной политики информацию, включая актуальный анализ и прогнознылй сценарий развития сочиально-политических институтов и прочессов, в том числе электоральных процессов 2021 года в России. Более того, указанныле технологии являются необходимыми инструментами политологического анализа и прогнозирования состояния и развития основных политических кластеров в условиях сочииально-экономического кризиса, интенсивного развития и использования электронной медиасреды.

Ключевые слова: политические кластеры, консолидации политической власти, политические технологии, сочиально-политический мониторинг, сочиально-медийная предиктивная аналитика (СМПА), общественно-политический менеджмент, сетевой партийный бренд, политическая мобилизация, киберпартии, электронная медиасреда.

Консолидация политической власти является приоритетной задачей для современной России, поскольку успешное решение данной задачи обеспечивает предпосылки и фундамент для эффективного решения проблемы устойчивого социально-политического и социально-экономического развития страны, демократической модернизации политической системы, общественно-политического консенсуса и политической мобилизации общества в целях реализации концепции национальной безопасности, решения стратегических задач общенационального уровня. Соответственно, возрастает 
необходимость поиска и применения, адекватных указанным задачам технологий осуществления политической власти, проведения в жизнь государственной консолидационной политики, своевременной адекватной оценки состояния и тенденций интегративных и дезинтегративных социально-политических процессов, политического предвидения и прогнозирования. Это, в свою очередь, актуализирует необходимость создания системы социально-политического мониторинга, в том числе в электронной медиасреде, как части государственной консолидационной политики.

Следует отметить, что актуальность социально-политического мониторинга и прогнозирования многократно возрастает в кризисные, переломные периоды развития страны, когда общество переживает социальные травмы и трансформации, а политические ошибки имеют долгосрочные негативные последствия. Очевидно, что современная Россия переживает именно такой кризисный период своего развития под влиянием внешних и внутренних неблагоприятных факторов. Среди внешних актуальных вызовов современности отметим внешнеэкономическое и политическое давление на Россию со стороны Запада, ситуацию пандемии, обострившую международную обстановку. Среди внутренних проблем следует выделить спровоцированные ситуацией пандемии безработицу и падение доходов населения, необходимость социальной защиты населения и разворачивающийся демографический кризис, а также ряд задач, которые приходится срочно решать власти по организации безопасных дистанционных режимов функционирования социально-политических институтов и процессов. Следует также принять во внимание актуальную ситуацию Выборов 2021 года, которая обостряет процессы политической борьбы и провоцирует социально политический раскол, как среди элит различного уровня власти, так и среди электората в целом. На этом фоне чрезвычайно возрастает вероятность информационной войны и идеологических диверсий, попыток внешнего вмешательства в электоральные и внутриполитические процессы посредством использования новых информационных технологий, информационной медиасреды.

Соответственно, организация своевременного социально-политического мониторинга текущей ситуации, выработка адекватных ситуации стратагем должны носить системный, оперативный, всесторонний, комплексный характер, обеспечивающий достоверный и прикладной характер полученных результатов. Информационная сфера, электронная медиасреда, соответственно, должна получить адекватные и эффективные технологии, с одной стороны, для организации управления и контроля информационных потоков, отслеживания вредоносного контента, характера политических манипуляций и т.д., а, с другой стороны - для развития информационных и электронных пространств в целях обеспечения широкого доступа граждан к достоверной политической информации, возможности полноценного участия граждан посредством электронных технологий в социально-политической жизни страны. 
Что касается организации социально-политического мониторинга общественного мнения, то с этой задачей в современной России достаточно эффективно справляется ВЦИОМ и другие центры опроса общественного мнения, которые проводят регулярные, как правило, еженедельные опросы россиян на актуальные темы, представляют в открытом доступе результаты - аналитические обзоры, аналитические доклады, рейтинги доверия политикам и политическим институтам, индексы протестной активности населения, статистические оценки социального благополучия и настроений в обществе. Некоторые политологи указывают на противоречивость предоставляемых центрами опроса общественного мнения данных, а также на чрезвычайное многообразие вариативность применяемых в опросах методик, что позволяет, опираясь на мониторинг по одной и той же теме, выявить противоположные тенденции развития политических процессов и институтов. Вместе с тем, указанное многообразие методик, подходов, способов оценки результатов мониторинга можно интерпретировать в положительном ключе, поскольку оно обеспечивает всесторонность исследования института общественного мнения, а также позволяет выявить не только явные, но и латентные социально-политические тенденции.

В качестве рекомендации в рамках темы консолидации политической власти, можно предложить организацию системного двухступенчатого мониторинга. На первом этапе общий обзорный мониторинг общественного мнения по актуальным вопросам. На втором - детальное, с применением разных методик, исследование по наиболее острым темам, дополнительное исследование вопросов, по которым были получены наиболее противоречивые результаты, результаты, нуждающиеся в детализации, уточнении, перепроверке и т.д. При достаточной регулярности и системности проведения опросов можно получить достоверную картину состояния института общественного мнения, использовать данные для вторичного анализа и концептуализации, социально-политического прогнозирования и реагирования, и в конечном итоге, обеспечить механизмы и процессы легитимации политической власти на уровне широкой общественности как неотъемлемую часть консенсуса власти и общества.

Что касается проблемы социально-политического мониторинга и прогнозирования в информационной электронной медиасреде, то здесь необходимы дополнительные инструменты анализа и технологии. Это связано не только с меньшей стабильность, предсказуемостью, большей мобильностью и гетерогенностью электронных социально-политических пространств, но и со специфическими особенностями социально-политических образований - сетевых кластеров, с сетевым интерактивным характером коммуникаций, присущим электронной медиасреде. Соответственно, в фокусе внимания политологов, должны быть технологии политической социализации и мобилизации в электронном пространстве социальных сетей, а также результаты социально-медийной аналитики. 
Социально-медийная предиктивная аналитика (СМПА) использует сетевой подход, постбихевиоризм, кибертехнический анализ, Predictor Mining для извлечения из сетевых информационных пространств необходимых смыслов, с целью последующего математического моделирования и картографирования информационных потоков и пространств, социально-политического прогнозирования, разработки и передачи рекомендаций заинтересованным субъектам политических процессов. Используя анализ цифровых следов в социальных медиа, социально-медийная предиктивная аналитика позволяет выявить тенденции трансформации сетевых политических акторов под влиянием медиасреды и электронных интеракций, а также оценить масштаб и потенциал использования политическими акторами информационных потоков. Так, например, исследования А. Реммелле показывают возможности использования информационных потоков в ходе избирательных компаний для организации определенного электорального выбора пользователей электронной медиасреды. Исследования цифровых интеракций политических партий в электоральных процессах С. Карлсен подтверждают тезис А. Чедвика о том, что развивающееся в формате электронной медиасреды противоречие между контролем и неопределенностью результатов интеракции приводит к трансформации основных акторов политических процессов [5].

Политические акторы в пространстве электронной медиасреды и под ее влиянием обретают характер сетевых кластеров, коммуникативные связи и конфигурация которых постоянно изменяются, воссоздаются посредством интеракции заново. Политические партии, например, в цифровых пространствах не способны поддерживать традиционный порядок организации, нормы партийной дисциплины и лояльности, поэтому они вынужденно трансформируются, адаптируясь к особенностям сетевой интеракции. Это приводит к трансформации политических субъектов и политической культуры в направлении конфигурации по типу сетевых кластеров, открывая не только новые смыслы и возможности взаимодействия по линии «власть общество», «политические партии - электорат» и т.д., но и размывая традиционные границы политических феноменов, расширяя возможности, цифровые способы влияния и манипулирования электоратом.

Присущее электронным медиапространствам таргетирование контента, возможность адресно предоставлять его целевой аудитории актуализирует феномен «подталкивающей информации» - информации, которая, не ограничивая свободу выбора пользователей сети, тем не менее, оказывает существенное влияние на результат сделанного ими выбора (постбихевиоризм). Это позволяет говорить, что технологии социально-политического анализа и мониторинга информационных пространств, управления интерактивной активностью пользователей выступают не только средствами политической диагностики, но и являются технологиями политической манипуляции. 
Следует отметить широкое использование социально-медийной предиктивной аналитики (СМПА) как инструмента и технологии консолидации политической власти, анализа гражданского общества, выявления индивидуальных электоральных предпочтений пользователей социальных сетей и т.д. в Западной Европе и США. Анализ гражданского общества, электората проводится с целью выявить наиболее уязвимые места в его сетевой конфигурации, определить точки наиболее эффективного применения общественно-политического менеджмента, чтобы привести сетевой кластер к конформному состоянию [3]. Так же, как показывают электоральные процессы в США, использование социальных сетей Фейсбук и Твитер в политических целях, получение пользователями сети определенной подталкивающей информации значительно влияет на результат электорального выбора. Тем более, что инструменты коммерческого таргетинга способны предоставить, составленные нейросетью, выборки пользователей с определенным психологическим профилем.

Немаловажно, что в пространстве современных социальных медиа функционируют не только и не столько цифровые представительства институциональных партий, сколько сетевые партийные бренды. То есть, маркетинговые технологии формирования и прогнозирования потребительского поведения активно используются в современной политической жизни для организации электоральной поддержки и политического участия, а также влияния на электоральный выбор пользователей сети.

Следует отметить, что сетевой партийный бренд - это, прежде всего образ и имидж партии, который распространяется в сети, поэтому маркетинговые технологии формирования бренда с целью повысить его узнаваемость, увеличить лояльность потребителей к нему и предопределить покупательский выбор в пользу конкретного бренда, становятся активным элементом формирования сетевых партийных брендов. Пользователь социальных медиа ориентируется не столько на букву политической программы, которую предлагает политическая партия, сколько на эмоционально-ассоциативный отклик, который вызывает у него тот или иной партийный бренд [4].

С одной стороны, это происходит в связи с объективными процессами цифровизации и виртуализации социума в XXI веке, а с другой стороны это обусловлено спецификой обращения пользователей социальных сетей с информационными потоками, особенностями обработки информации и виртуальных коммуникаций.

Современный пользователь социальных сетей перегружен информацией. В условиях переизбытка информации и ограниченности способности ее критически обрабатывать, человек делает выбор в пользу узнаваемых брендов. Соответственно брендирование политических партий и объединений, технологии захвата потребителей политического контента аналогичны маркетинговым технологиям привлечения и управления целевой 
аудиторией. Технологии анализа управления информационными потоками в сети, методы социально-медийной аналитики, в свою очередь, позволяют достаточно точно выявлять тенденции электорального поведения и предсказывать результаты электорального выбора, что делает их необходимыми элементами современных политических процессов и институтов осуществления власти.

В ситуации масштабных Выборов 2021 года в сентябре в России, использование результатов социально-медийной предиктивной аналитики должно стать неотъемлемой частью социально-политического мониторинга в раках государственной консолидационной политики. Так, например, актуальный мониторинг цифровых пространств, позволяет сделать прогноз относительно того, изменится ли партийная конфигурация парламентских партий, получат ли электоральные ожидания сторонников непарламентских партий возможность реального воплощения в политических пространствах в результате Выборов в сентябре 2021 года, а также выработать ряд рекомендаций для политических партий по управлению информационными потоками и масштабированию электоральной поддержки в социальных сетях. Социально-политическое прогнозирование опирается на такие параметры информационной активности политических партий в социальных медиа как представленность в электронной медиасреде, а также объем, плотность, равномерность информационных коммуникационных потоков, охват и рост аудитории, процент «ботовости» аудитории (увеличение аудитории за счет программ-роботов, а не реальных пользователей) и т.д.

Киберметрический анализ 2021 года показывает, что наибольший вес среди парламентских партий у информационного потока партии «Единая Россия» - 59,4\%, 20,4\% - «КПРФ», 14,8\% - «ЛДПР», 3,6\% - «Справедливая Россия». Среди непарламентских партий наибольший вес у информационного потока партии Яблоко - 16,2\%, Партия Роста - 15,7\%, Партия Пенсионеров - 13,5\%, Родина - 12,5\%, Парнас - 10,7\%. Партии Зеленая Альтернатива, За Правду, Коммунисты России замыкают линейку представленных в сети непарламентских партий [1]. Немаловажно, что, несмотря на то, что парламентские кластеры доминируют в медийном пространстве по количеству упоминаний и обладают сложной разветвленной структурой, активность их интеракций неравномерна, заметно повышается в предвыборный период. Непарламентские кластеры, несмотря на меньший вес информационных потоков, демонстрируют более эффективный общественно-политический менеджмент: открытость, неформальность, использование разнообразных сегментов сети, в том числе развлекательных информационных площадок, что позволяет им поддерживать стабильность коммуникации с электоратом, постоянный ритм. Вместе с тем, непарламентские партии имеют меньший ресурс и возможность масштабирования электоральной поддержки в сети. Соответственно, прогноз электорального 
потенциала спрогнозирован с учетом корректировки избирателей по возрасту следующим образом: 23,84\% - ЕП, 13,41\% - КПРФ, 19,37\% - ЛДПР, 18,78\% - СР, 9,37\% - Новые люди, 4,88\% - За правду, 0,63\% - Зеленая Альтернатива, 2,28\% - Парнас, 0,20\% - Патриоты России, 6,05\% - Партия Роста [1]. Немаловажно, что именно благодаря своевременному общественнополитическому мониторингу и эффективному менеджменту, использования инструментов и технологий социальных медиа, такие партии как, например, партия «Новые люди» получают шанс быть представленными в парламенте на предстоящих выборах. Поэтому политологам следует обращать внимания на динамику развития политических сетевых брендов и особенности использования ими информационных потоков при решении проблем консолидации политической власти [2].

Подытожим. Применительно к реалиям России 2021 года, социальнополитический мониторинг и социально-медийная предиктивная аналитика (СМПА) являются эффективными востребованными инструментами и технологиями консолидации политической власти, способными предоставить необходимую для обеспечения государственной консолидационной политики информацию, включая актуальный анализ и прогнозный сценарий развития социально-политических институтов и процессов, в том числе электоральных процессов 2021 года в России. Более того, указанные технологии являются необходимыми инструментами политологического анализа и прогнозирования состояния и развития основных политических кластеров в условиях социально-экономического кризиса, интенсивного развития и использования электронной медиасреды.

\section{БИБЛИОГРАФИЧЕСКИЙ СПИСОК:}

1. Бродовская Е.В., Домбровская А.Ю. Конкуренция информационных потоков российских политических партий (2020-2021 г.): основные результаты социально-медийной предиктивной аналитики // https://event.wciom. ru/file/report_2021/115_21052021094245.pdf.

2. Бродовская Е.В., Лифанова В.А., Лукушин В.А., Семенова М.С. Цифровые инфраструктуры традиционных и новых российских политических партий: масштаб и функциональность (2020) // Социально-гуманитарные знания. 2021. № 3 .

3. Евсеев B.O. Гражданское общество России через призму зарубежных методик // https://event.wciom.ru/file/report_2021/113_21052021094030.pdf.

4. Писарчук Д.И. Сетевой партийный бренд как феномен нового экстрасоциального общества // Вестник РГГУ. Серия: Политология. История. Международные отношения. 2014. № 1 (123).

5. Chadwick A., Stromer-Galley J. Digital Media, Power, and Democracy in Parties and Election Campaigns // International Journal of Press/Politics. 2016. No 21. 
6. Margetts $H$. The cyber party // School of Public Policy, Univ. College London; Paper to workshop 'The Causes and Consequences of Organisational Innovation in European Political Parties', ECPR Joint Sessions of Workshops. Grenoble, 6-11 April, 2001.

\author{
A.V. OSIPOV \\ Candidate of Political Science, \\ Judge of the Leninsky District Court of Rostov-on-Don, \\ Rostov-on-Don, Russia
}

\title{
SOCIO-POLITICAL MONITORING AND SOCIO-MEDIA PREDICTIVE ANALYTICS AS TOOLS AND TECHNOLOGIES FOR CONSOLIDATING POLITICAL POWER
}

Assessing the data obtained by the centers of public opinion poll and SMPA in 2020-2021, the author justifies the conclusion that socio-political monitoring and socio-media predictive analytics (SMPA) are effective popular tools and technologies for consolidating political power, capable of providing the information necessary to ensure state consolidation policy, including current analysis and a forecast scenario for the development of socio-political institutions and processes, including the electoral processes of 2021 in Russia. Moreover, these technologies are necessary tools for political analysis and forecasting the state and development of the main political clusters in conditions of socio-economic crisis, intensive development and use of the electronic media medium.

Key words: political clusters, consolidation of political power, political technologies, socio-political monitoring, socio-media predictive analytics (SMPA), socio-political management, network party brand, political mobilization, cyber parties, electronic media environment. 